\title{
Curly-tail mice with neural tube defects show abnormal cortical development
} Sarah Cains ${ }^{1}$, Chloe Duval ${ }^{1}$, Dawn Savery ${ }^{2}$, Hussain Moudahi ${ }^{1}$, Andrew Copp ${ }^{2}$ and Jaleel Miyan*1 \author{
Development Unit, Institute of Child Health, UCL, 30 Guilford Street, London, WC1N 1EH, UK \\ Email: Jaleel Miyan* - j.miyan@manchester.ac.uk \\ * Corresponding author \\ from 52nd Annual Meeting of the Society for Research into Hydrocephalus and Spina Bifida \\ Providence, RI, USA. II-I4 June 2008 \\ Published: 3 February 2009 \\ Cerebrospinal Fluid Research 2009, 6(Suppl I):S22 doi:I0.1186/I743-8454-6-SI-S22
}

Address: ${ }^{1}$ Faculty of Life Sciences, The University of Manchester, 1.124 Stopford Building, Oxford Road, Manchester M13 9PT, UK and ${ }^{2}$ Neural

This abstract is available from: http://www.cerebrospinalfluidresearch.com/content/6/SI/S22

(C) 2009 Cains et al; licensee BioMed Central Ltd.

\section{Background}

Our past work suggests a vital role for cerebrospinal fluid (CSF) in normal cortical development. Abnormal cortical development occurs from the earliest stages following fluid obstruction in the developing brain of a hydrocephalic fetus. Here, we studied development of the cerebral cortex in the curly-tail mouse model of neural tube defects (NTDs). Curly tail litters exhibit a variety of NTDs including exencephaly and spina bifida. A proportion of littermates have no apparent defect.

\section{Materials and methods}

Homozygous curly-tail mice were time-mated and injected with 2, bromodeoxyuridine (BrdU, $60 \mathrm{mg} / \mathrm{kg}$ ) on day E17. Fetuses were harvested on day E19 and fixed in $4 \%$ paraformaldehyde. After cryoprotection in 20\% sucrose, whole fetuses were sectioned at $25 \mu \mathrm{m}$ on a Leica cryostat. Sections were air dried before immunocytochemical staining with anti-BrdU antibody (Nova Castro, UK). Images were taken on a Leica DMLB microscope using a Coolsnap camera (Princeton Instruments) and Metaview Software (Universal Imaging).

\section{Results}

Curly tail fetuses with exencephaly showed almost total degeneration of the cortex, as a result of exposure of the neuroepithelium to amniotic fluid. Among curly-tail fetuses with a closed brain, all but one showed abnormal migration of BrdU labelled cells. This varied from no apparent migration from the germinal epithelium to a random pattern of stained cells throughout the different zones of the cortex. This compared to the laminar distribution of labelled cells at the top of the cortex, adjacent to the marginal zone, in normal control mice.

\section{Conclusion}

While exencephaly is associated with degeneration of the neuroepithelium, mice with a genetic predisposition to neural tube defects show abnormal development of the cerebral cortex, specifically with disturbance of the migration of cells from the germinal zone into the developing cortex. 